\title{
Induction of phenolic compounds in Hypericum perforatum L. cells by Colletotrichum gloeosporioides elicitation
}

\author{
Luis F.R. Conceição ${ }^{\text {a }}$, Federico Ferreres ${ }^{b}$, Rui M. Tavares ${ }^{a}$, Alberto C.P. Dias ${ }^{\text {a,* }}$ \\ ${ }^{a}$ University of Minho, Department of Biology, Campus de Gualtar, 4710-057 Braga, Portugal \\ ${ }^{\mathrm{b}}$ Research Group on Quality, Safety and Bioactivity of Plant Foods, CEBAS (CSIC), P.O. Box 4195, Murcia 30080, Spain
}

Received 6 May 2005; received in revised form 14 October 2005

Available online 1 December 2005

\begin{abstract}
Changes in phenolic metabolism after elicitation with Colletotrichum gloeosporioides (CG) has been studied in Hypericum perforatum L. (HP) cell suspension cultures. Soluble phenolics were analysed by HPLC-DAD and HPLC-DAD-MS/MS. HP cultures elicited with the CG elicitor showed a significant increase in xanthone accumulation. Xanthone accumulation increased twelve fold when the cells were primed with methyl-jasmonate (MeJ) or salicylic acid (SA), before elicitation. HP cultures exposed only to MeJ produced a set of flavonoids, the flavones which represent a substantial part (approx. 40\%) of the total flavonoids accumulated in these cells. The possible importance of xanthones as a component of defence mechanism of HP against biotic stress is discussed.
\end{abstract}

(C) 2005 Elsevier Ltd. All rights reserved.

Keywords: Hypericum perforatum; Colletotrichum gloeosporioides; Phenolics; Xanthones; Biotic stress; Methyl-jasmonate; Salicylic acid; HPLC-DADMS/MS

\section{Introduction}

Hypericum perforatum L. (St. John's wort) is a medicinal plant used all over the world. Extract of HP is widely used to treat mild to moderate depression. The efficacy of the extract has been supported by some pharmacological and clinical studies (Erdelmeyer et al., 2000; Izzo and Ernst, 2003; Butterweck, 2003), attracting the interest of pharmaceutical industries. Presently, HP is one of the leading medicinal herbs sold both in EU and in USA (Erdelmeyer et al., 2000).

The growing demand for HP-derived products and their phytochemical consistency lead the producers to utilize the biomass of cultivated plants instead of wild collection. Nowadays, HP cultivation covers several hundred hectares in Europe (Gaudin et al., 2003). Most of these plants are

\footnotetext{
* Corresponding author. Tel.: +351 253604317/18; fax: +351 253678980.

E-mail address: acpdias@bio.uminho.pt (A.C.P. Dias).
}

grown organically, so they are highly exposed to pathogens. One of the main problems concerning the long-term cultivation of HP is the fungal disease anthracnose caused by Colletotrichum gloeosporioides (Gaudin et al., 2003). This pathogen is responsible for heavy losses in HP plantations by lowering yield and modifying the chemical composition of the plant extracts. Several efforts have been taken to obtain HP plants resistant to anthracnose. Nevertheless, little is known about the defence responses of this plant against pathogen attack. Differential accumulation of hyperforin and hypericin after elicitation of $H$. perforatum plantlets with $C$. gloeosporioides was reported (Gibson and Sirvent, 2002).

Plant cell cultures of several species have been utilized, successfully as models to study the biochemical changes related to plant defence responses against pathogens (Hagemeier et al., 1999; Conrath et al., 2002; Hahlbrock et al., 2003). This system is relatively easy to manipulate and provide a better control of external factors that can interfere with the metabolic activities and thus advantageous over in vivo plant-pathogen interaction. 
Here, we report the utilization of HP cell suspension cultures as a tool to study the defence responses related to phenolic metabolism against $C$. gloeosporioides attack

\section{Results}

\subsection{Phenolic profiles of non-elicited and elicited H. perforatum cultures}

Fig. 1(a) shows a typical HPLC profile of the phenolics produced by HP cell cultures (control). A major group of compounds were putatively identified as xanthone derivatives with $1,3,6,7$ oxygenation pattern based on their characteristic UV spectra previously (Dias et al., 2000, 2001). A major xanthone (compound X1) was putatively identified as mangiferin. HPLC-MS/MS analysis of this compound gave a molecular ion $\mathrm{m} / z[\mathrm{M}-\mathrm{H}]^{-}$of 421.5 and major $\mathrm{MS}^{2}$ fragments at $\mathrm{m} / \mathrm{z} 331.0[\mathrm{M}-\mathrm{H}-90]^{-}$and 301.2 $[\mathrm{M}-\mathrm{H}-120]^{-}$, losses characteristics of C-hexosyl compounds (Cuyckens et al., 2001). HPLC-DAD-MS/MS comparison analysis with a commercial standard of mangiferin (Extrasynthèse, Genay, France) confirmed this identification. Xanthones $\mathbf{X} 7$ and $\mathbf{X 1 0}$ were identified as 1,3, 7-trihydroxy-6-methoxy-8-prenylxanthone (molecular ion $m / z[\mathrm{M}-\mathrm{H}]^{-}$of 341.5 ) and $\gamma$-mangostin (molecular ion $m / z[\mathrm{M}-\mathrm{H}]^{-}$of 395.5$)$, respectively, by HPLC-DAD and HPLC-MS-MS comparisons with pure compounds previously isolated from Hypericum androsaemum cell cultures (Dias et al., 2000). Several other minor compounds were categorized as 1,3,6,7-xanthone derivatives by HPLC-DAD-MS/MS analysis, but not fully identified.

A second set of phenolics (F2-F4) produced by HP cell cultures were identified as flavonols based on their characteristic UV spectra. An intense deprotonated ion of the aglycone $(\mathrm{m} / \mathrm{z} 300.2)$ was observed for these compounds indicating that they are quercetin derivatives. Compounds F2 and F3 contained similar deprotonated molecular ion $\mathrm{m} / \mathrm{z}$ at 463.6 and a major $-\mathrm{MS}^{2}$ fragment at $\mathrm{m} / \mathrm{z} 301.0$, corresponding to the loss of a hexoside residue from quercetin aglycone. Commercial standards (Extrasynthèse, Genay, France) were used to confirm the compound $\mathbf{F 2}$ as hyperosid and F3 as isoquercetrin. Compound F4 shared similarity with F2 and F3 in UV-spectra indicating its quercetin 3-derivative nature. It has a deprotonated molecular ion at $\mathrm{m} / \mathrm{z} 505.2$ and $-\mathrm{MS}^{2}$ fragments at $\mathrm{m} / \mathrm{z}$ of 462.7 $[\mathrm{M}-\mathrm{H}-42]^{-}$(quercetin 3-hexoside), that resulted from the loss of an acetyl group, and $\mathrm{m} / \mathrm{z}$ of 301.0 (quercetin aglycone). According to its UV and mass spectra, this compound could be an acetyl derivative of hyperoside or isoquercetrin, a compound recently identified in HP plants (Silva et al., 2005).

HP cells primed with $\mathrm{MeJ}$ produced several compounds that were not detected in the control cells (Fig. 1(b), compounds F1, F5-F10). Compound F1 has shown a similar UV and MS-MS spectra $(\mathrm{m} / \mathrm{z}$ of 463.8 and 301.0) to those of compounds F2 and F3 indicating that it is a quercetin-3- hexose derivative. Compounds F5-F10 were identified as flavone derivatives. Compounds F5 and F6 have a deprotonated molecular ion at $m / z 447.9,-\mathbf{M S}^{2}$ fragment at $\mathrm{m} / \mathrm{z}$ of 285.7 (aglycone) and a similar UV spectra $(267,339)$. They were characterized tentatively as 6- and/or 8-OH-apigenin7-hexosides based on their UV and MS-MS spectra. Compound F9 was identified as luteolin-C-prenyl by HPLC-DAD-MS/MS after comparison with pure compound previously isolated from $H$. androsaemum cell cultures (Dias et al., 1998). Compounds F7, F8 and F10 were also assigned as luteolin derivatives due to their UV spectra $(255,277,346)$ and the presence of an intense $\mathrm{MS}^{2}$ fragment at $\mathrm{m} / z$ of 285.9 . Cells primed only with SA did not produce any new compounds.

Several compounds were produced de novo in HP cultures when elicited with CG (Fig. 1(c)) mainly in those cells previously primed with MeJ (Fig. 1(d)). On perusal of the profile of UV spectra, the compounds were identified as 1,3,6,7 xanthone derivatives. Similar HPLC profiles were obtained when the cultures were first primed with SA and then elicited with CG extract (results not shown). Compound X2 was identified as 1,3,6,7-tetrahydroxyxanthone aglicone (single intense molecular ion $\mathrm{m} / z[\mathrm{M}-\mathrm{H}]^{-}$of 259.9). Compound $\mathbf{X} \mathbf{3}$ was putatively identified as mangiferin- $C$-prenyl. HPLC-MS/MS analysis of this compound gave a molecular ion $\mathrm{m} / z[\mathrm{M}-\mathrm{H}]^{-}$of 489.6 and major $\mathrm{MS}^{2}$ fragments at $\mathrm{m} / \mathrm{z} 399.1[\mathrm{M}-\mathrm{H}-90]^{-}$and 369.2 $[\mathrm{M}-\mathrm{H}-120]^{-}$, losses characteristics of C-hexosyl compounds (Cuyckens et al., 2001). Compound X4 gave a molecular ion $m / z[\mathrm{M}-\mathrm{H}]^{-}$of 517.7 , major $-\mathrm{MS}^{2}$ fragments at $\mathrm{m} / \mathrm{z}$ of 365.0 and an intense fragment at $\mathrm{m} / \mathrm{z}$ of 257.1 characterized it as a dimer of 1,3,6,7-tetrahydroxyxanthone. Compounds X5 and X6 had an UV spectra characteristic of 1,3,6,7-oxygenated xanthones and molecular ion $m / z[\mathbf{M}-\mathbf{H}]^{-}$of 326.9. So, these compounds were identified as $1,3,6,7$-tetrahydroxyxanthone- $C$-prenyl isomers. Compounds $\mathrm{X} 8, \mathrm{X} 9$ and $\mathrm{X} 11$ were putatively identified as isomers of $\gamma$-mangostin (1,3,6,7-tetrahydroxyxanthone$C$-bis-prenyl), since they have a similar molecular ion $\mathrm{m} / \mathrm{z}$ $[\mathrm{M}-\mathrm{H}]^{-}$of 395.4 but different UV spectra and retention times. Several minor compounds were also identified as 1,3,6,7-tetrahydroxyxanthone derivatives but their identification was not fully accomplished.

\subsection{Differential accumulation of phenolics due to MeJ and $S A$ priming and $C G$ elicitation}

Fig. 2 shows the accumulation of major phenolic groups after $24 \mathrm{~h}$ of CG elicitation in seven days old HP suspension cultures.

HP suspension cultures elicited with the fungal elicitor showed a significant increase (seven fold) in xanthone accumulation. This burst was due to an increased production of usual xanthones (like $\mathbf{X} \mathbf{7}$ and $\mathbf{X 1 0}$ ) as well as the synthesis of new ones (Fig. 1(c)). This effect was particularly noticeable when the cells were primed with MeJ prior to elicitation with CG (Fig. 1(d)). In this condition, total 

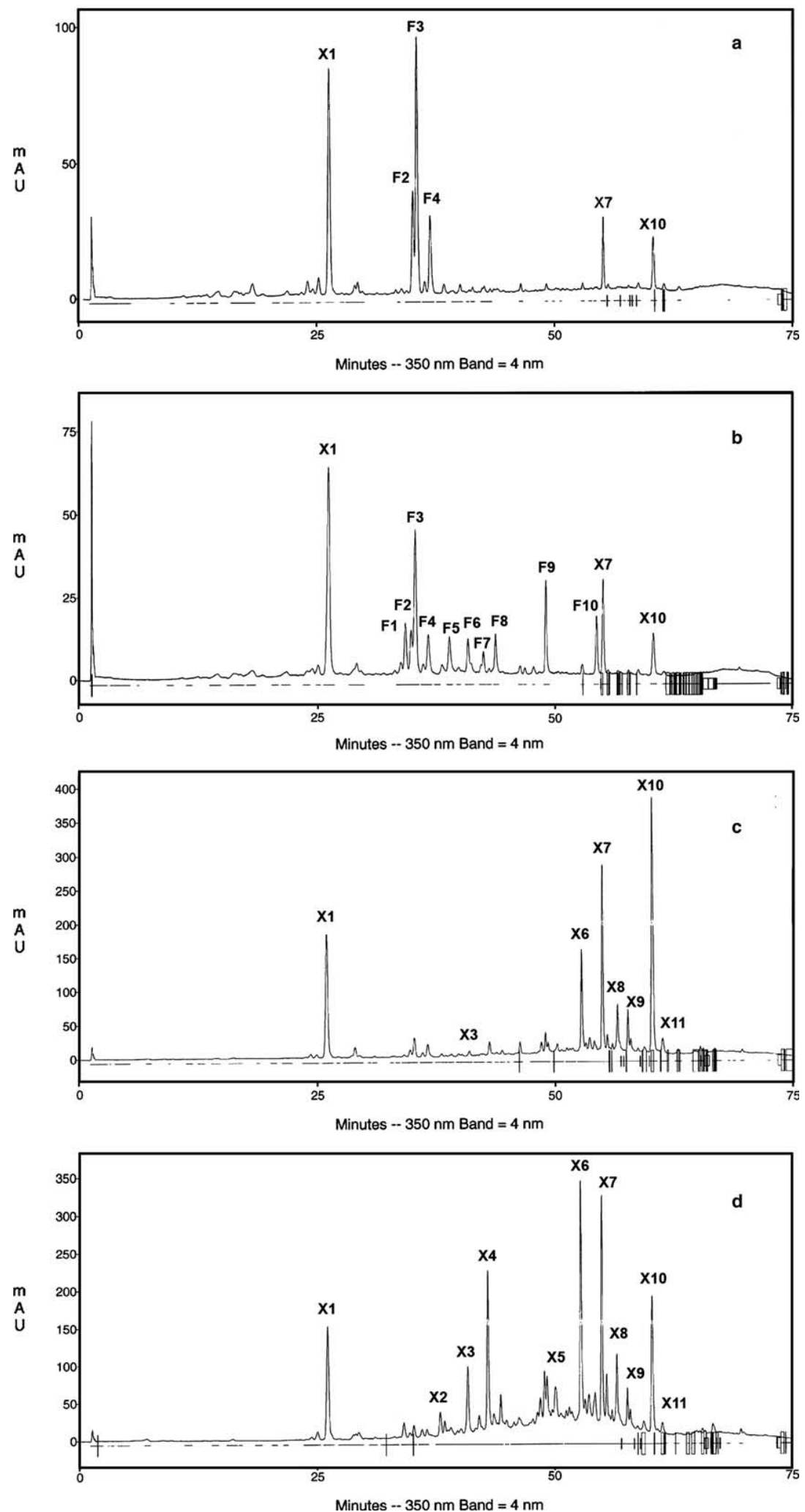

Fig. 1. HPLC-DAD chromatograms of methanolic extracts from H. perforatum cells, at the 7th day of growth: (a) control samples; (b) MeJ-treated cultures; (c) cultures elicited with C. gloeosporioides elicitor; (d) cultures primed with MeJ, prior to C. gloeosporioides elicitation. Compounds: X1 mangiferin; X2 - 1,3,6,7-tetrahydroxyxanthone; X3 - mangiferin- $C$-prenyl; X4 - 1,3,6,7-tetrahydroxyxanthone dimer; X5, X6 - 1,3,6,7-tetrahydroxyxanthone- $C$-prenyl isomers; X7 - 1,3,7-trihydroxy-6-methoxy-8-prenylxanthone; X8, X9, X11 - isomers of $\gamma$-mangostin; X10 - $\gamma$-mangostin $(1,3,6$, 7-tetrahydroxyxanthone-bis-prenyl). F1 - quercetin-3-hexose derivative; F2 - hyperosid; F3 - isoquercetrin; F4 - acetyl quercetin-3-hexoside; F5 and F6 glycoside apigenin derivatives; F7, F8 and F10 - luteolin derivatives; F9 - luteolin- $C$-prenyl. 


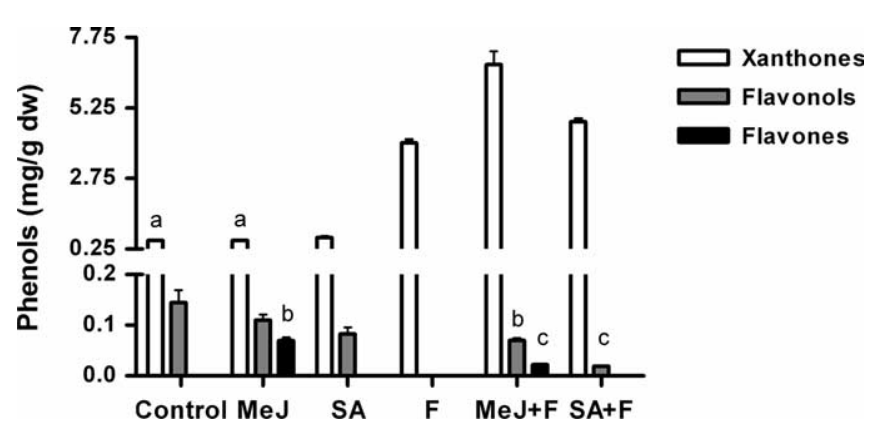

Fig. 2. Total phenols produced by cell cultures of $H$. perforatum at the 7 th day of growth, $24 \mathrm{~h}$ after fungal elicitor addition. Cultures were treated with $\mathrm{MeJ}(100 \mu \mathrm{M})$, SA $(25 \mu \mathrm{M})$, or $C$. gloeosporioides elicitor $(\mathrm{F})$. The bars indicated as $\mathrm{MeJ}+\mathrm{F}$ and $\mathrm{SA}+\mathrm{F}$ correspond to cells primed with MeJ $(100 \mu \mathrm{M})$ or SA $(25 \mu \mathrm{M})$, respectively, before the addition of the fungal elicitor. Results are means $( \pm \mathrm{SD})$ of six independent replicates from two independent experiences. All the values are statistically different $(P<0.05)$ except those signalised with the same letter.

xanthone content increased approximately twelve times when compared to the control (Fig. 2). Addition of SA alone to HP cultures also increased xanthone accumulation significantly $(P<0.05)$.

Flavonoids accumulation in HP suspension cultures was also changed considerably after priming and elicitation procedures (Fig. 2). Flavonoids were not detected in cells exposed only to the fungal elicitor. Accumulation of these compounds decreased in the cells primed with MeJ or SA followed by $\mathrm{CG}$ elicitation $(P<0.05)$. HP suspension cultures exposed only to MeJ produced a new class of flavonoids, the flavones (Fig. 2). Flavones represent a significant proportion (approx. $40 \%$ ) of the total flavonoids accumulated in those cells. Interestingly, in this condition, the total accumulation of flavonoids (flavonols plus flavones) did not change significantly from the control $(P>0.05)$.

In spite of the significant changes in the accumulation of different phenolic classes, the total amount of phenolics produced by MeJ and SA-elicited cells was not statistically different to that of the control. However, cells elicited with $\mathrm{CG}$ elicitor produced a higher amount of phenols, mainly due to the increase in xanthone accumulation (Fig. 2).

\subsection{Time course changes of phenolic accumulation in cells due to MeJ and $S A$ priming and CG elicitation}

The elicitation process also induced significant changes in the phenols accumulated by the cells throughout the culture period (Fig. 3). HPLC analysis of the cell culture medium did not show any traces of phenolics at any stage of the culture. Moreover, cell viability remained high (around $90 \%$ ) in all the tested conditions. Apparently, the phenolics produced were either accumulated or metabolized intracellularly. Similar results have been described for the accumulation of xanthones in Centaurium species (Beerhues and Berger, 1995).

In the cell suspensions elicited only with MeJ, xanthone accumulation remained constant throughout the culture
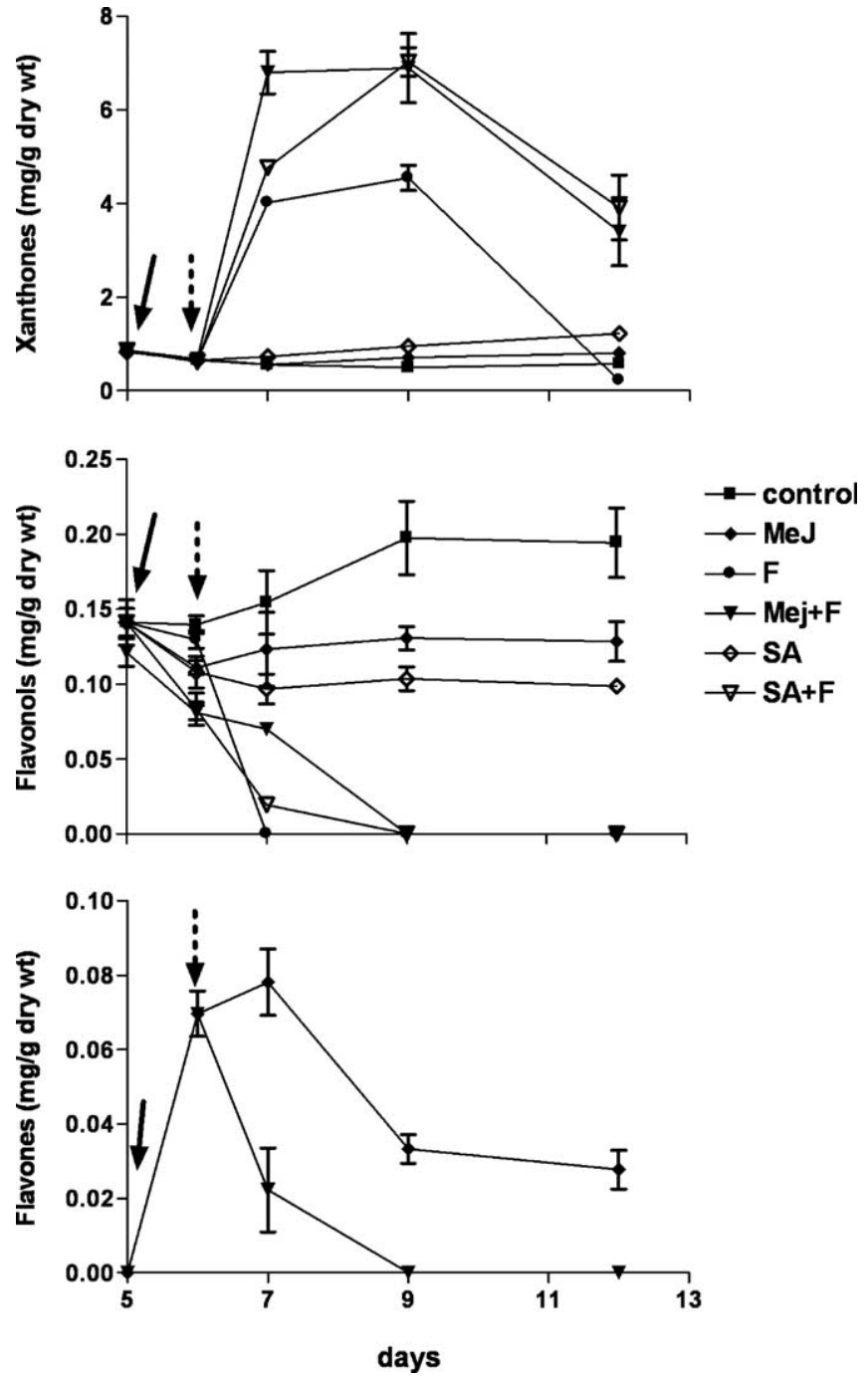

Fig. 3. Accumulation of phenolic compounds by cell suspension cultures of H. perforatum, throughout growth period, treated with $\mathrm{MeJ}(100 \mu \mathrm{M})$, SA $(25 \mu \mathrm{M})$, or $C$. gloeosporioides elicitor $(\mathrm{F})$. The samples indicated, as $\mathrm{MeJ}+\mathrm{F}$ and $\mathrm{SA}+\mathrm{F}$ were cells primed with $\mathrm{MeJ}(100 \mu \mathrm{M})$ or SA $(25 \mu \mathrm{M})$, respectively, before the addition of the fungal elicitor. Results are means $( \pm \mathrm{SD})$ of six independent replicates from two independent experiences. The straight arrow indicates the addition of SA or MeJ, and the dotted arrow indicates addition of fungal elicitor.

period (Fig. 3). However, cells elicited with SA only showed a significant increase in xanthone production with culture period $(P<0.05)$.

Xanthone level of HP cells primed with $\mathrm{MeJ}$ reached the maximum in $24 \mathrm{~h}$ after the addition of CG elicitor (Fig. 3). Cell suspensions treated with fungal elicitor with or without SA priming attained the highest xanthone accumulation only after $72 \mathrm{~h}$ of elicitor addition. After day 9, the amount of xanthones started decreasing gradually. By the day 12 , control and cells elicited with CG elicitor produced the same amount of xanthones. However, cells primed with $\mathrm{MeJ}$ and SA prior to fungal elicitor addition have retained the higher xanthone level even after 12 days (Fig. 3).

$\mathrm{MeJ}$ and SA addition to the suspension significantly decreased the accumulation of flavonols in HP cells at 
the end of the culture period (Fig. 3). Flavonols accumulation in HP suspension cultures were negatively affected by the addition of $\mathrm{CG}$ elicitor, resulting in their rapid disappearance throughout the culture time. It is interesting to mention that this disappearance coincided with the onset of xanthone production (Fig. 3).

Addition of MeJ to HP cells induced the synthesis of a new group of phenolic compounds, the flavones, which accumulated during the first $48 \mathrm{~h}$ after $\mathrm{MeJ}$ addition and subsequently declined (Fig. 3). Addition of the fungal elicitor to those cells resulted in a fall of flavone levels until they could no longer be detected after $72 \mathrm{~h}$.

\section{Discussion}

In the presence of a pathogen, plants develop a vast array of metabolic defence responses sequentially activated in a complex multicomponent network that may be local and/or systemic (Hahlbrock et al., 2003). Defence responses to pathogen infection include the production of several secondary metabolites such as phenolics (Dixon and Paiva, 1995; Dixon, 2001; Tan et al., 2004).

In the present study, HP cell suspension cultures developed a differential phenolic response upon $\mathrm{CG}$ elicitation which includes an increase in xanthone accumulation and the production of new constituents (Fig. 1(c)). Beerhues and Berger (1995) already observed an increase in the accumulation of new xanthones in the cultures of Centaurium sp., upon elicitation with yeast but not with the cell wall preparations of various pathogenic fungi. Xanthones are known for their pharmacological activities (Hostettmann and Hostettmann, 1989) such as antibacterial and anti-fungal (Beerhues et al., 2000; Braz-Filho, 1999). In addition, xanthones produced by $H$. androsaemum cell cultures have shown to inhibit the growth of Candida utillis and Saccharomyces cerevisae (Dias, 2003). In the present study, HP cell cultures elicited with fungal elicitor accumulated a significant amount of mangostin, a xanthone known to display anti-fungal activity (Hostettmann and Hostettmann, 1989). Moreover, a major part of the xanthones accumulated after elicitation have an non-polar nature which renders higher antimicrobial activity to the compounds. Therefore, the increase in xanthone accumulation observed in HP cells can be described as a defence response triggered by some of the components present in the fungal elicitor. It is known that several fungal products such as proteins, glycoproteins or oligosaccharides can trigger the defence mechanisms in plants (Dmitriev, 2003).

The increase of xanthone accumulation observed in HP cultures after the treatment with fungal elicitor could be the reason why flavonols became undetectable after elicitation (Fig. 1(c) and (d)). It is known that xanthones and flavonoids are biosynthetically related compounds, sharing a pool of precursors (Schröder, 1997; Dias, 2003; Liu et al., 2003). Those precursors could have been shifted for the xanthones biosynthesis in detriment to the flavonoid path- way resulting in a too low flavonol production to detect by HPLC.

Plant defence can be triggered by local recognition of pathogens but, more effective responses include systemic signalling pathways (Conrath et al., 2002). Two of the most important compounds having this ability are salicylic acid (SA) and jasmonic acid (JA). Systemic responses include those dependent on SA signalling and are named Systemic Acquired Resistance (Dempsey et al., 1999). The Induced Systemic Resistance is known to be dependent on JA (Feys and Parker, 2000). SA, JA and its derivatives like MeJ have been used as inducers in plants and were found to stimulate their secondary metabolism (Hahlbrock et al., 2003; Thomma et al., 2000). For this reason we evaluated the possible effects of those molecules on the phenolic composition of HP cell suspensions. The overall increase in xanthone production and the quick response of HP cells to the CG elicitor (Figs. 2 and 3) after the pre-treatment with MeJ or SA suggests that these molecules primed the HP cells defences. This faculty is known for a long time but progress in understanding is still scarce (Conrath et al., 2002). The ability of jasmonate to boost plant defences against fungal pathogens has already been reported (Thomma et al., 2000). The mechanism of action of SA and MeJ (or more general, jasmonates) is still a mater of debate (Felton and Korth, 2000). These two compounds seem to act independently via antagonistic pathways giving rise to different plant responses. Nevertheless, a clear dichotomy does not always exist. In our case, both SA and MeJ were able to induce the priming of the xanthone accumulation in HP cells, as a response to the fungal elicitation, at different levels. However, significant differences were observed (Figs. 2 and 3). SA was able to increment the production of xanthones by itself, whereas $\mathrm{MeJ}$ alone did not interfere significantly in xanthone biosynthesis but resulted in a selective accumulation of flavones. The physiological significance of this pattern is not clear but might indicate that SA and MeJ stimulate different pathways in HP cells, independently of the result being the same: priming of the xanthone biosynthesis due to fungal elicitation.

The use of JA and SA in HP cell suspension was already reported (Vivanco et al., 2002). The authors have observed that the utilization of JA originated an increase in hypericin production of HP cultures. On the contrary, this response was not observed when SA or a pathogen extract was used. The elicitation of HP plantlets with SA, MeJ and C. gloeosporioides resulted in a differential accumulation of hyperforin and hypericin depending on the treatments (Gibson and Sirvent, 2002). Moreover, hypericin proved to inhibit the growth of $C$. gloeosporioides. Thus hyperforin and hypericin could be considered as presumptive phytoantecipins of HP. In our case, we did not observe the accumulation of either hypericin or hyperforin in HP cultures after elicitation with $\mathrm{CG}$, in agreement with previous studies (Dias, 2003). This could be due to the fact that compounds like hypericins are accumulated in specialized tissues (glands) and not in cells of an undifferentiated state. 
In conclusion, the accumulation of xanthones in HP cultures was strongly induced by CG elicitation especially when primed with SA and, namely MeJ. The results indicate that these compounds could act as defence compounds in HP cells, and eventually in in vivo plants. HP plants do not accumulate xanthones in significant amounts at the aerial parts, with the exception of mangiferin (Kitanov and Nedialkov, 1998). Nevertheless, we detected other xanthones in the biomass of HP plants occasionally (unpublished results). Taking in account the results presented here, this could be due to a biotic stress suffered by the plants in field conditions. Further studies are needed to validate this thesis. Additionally, isolation of the major xanthones produced by HP cells due to the elicitation process are ongoing, to test their potential activity against C. gloeosporioides.

\section{Experimental}

\subsection{Materials}

All solvents (HPLC grade) were purchased from Merck (Darmstadt, Germany). Milli-Q water was generated by deionization (Millipore, MA, USA). Chemicals (analytical grade) utilized in the study were obtained from Sigma (Barcelona, Spain) except that of mangiferin and flavonoid standards which were supplied by Extrasynthèse (Genay, France).

\subsection{Media and growth conditions}

Cell suspension cultures of HP were obtained and maintained as described elsewhere (Dias et al., 2001). The cultures were incubated in 16-h light photoperiod, illuminated by fluorescent light bulbs (Osram-Fluora) providing a photon flux of $30 \mu \mathrm{mol} \mathrm{s}{ }^{-1} \mathrm{~m}^{-2}$. Each Erlenmeyer flask containing $70 \mathrm{ml}$ MS liquid medium was inoculated with $10 \mathrm{ml}$ of suspension at the late exponential phase and kept on a rotary shaker at $100 \mathrm{rpm}$, at $25^{\circ} \mathrm{C}$. Cells were sub-cultured regularly to fresh medium once in every 14 days.

\subsection{Fungal elicitor preparation}

Cultures of C. gloeosporioides were maintained in potato dextrose agar (PDA) plates incubated in dark, at room temperature. Flasks containing modified liquid Mathur's medium (Freeman et al., 2000) were inoculated with 4-5 PDA agar plugs containing young C. gloeosporioides mycelium and kept in the dark at $25^{\circ} \mathrm{C}$ in a rotary shaker at $250 \mathrm{rpm}$. Fully-grown liquid cultures were obtained 14 days after inoculation. Biomass of $C$. gloeosporioides was harvested by filtration, lyophilized for $48 \mathrm{~h}$ and crushed in a mortar. The crushed fungal biomass was put in water $\left(20 \mathrm{mg}\right.$ dry $\mathrm{wt} / \mathrm{ml}$ ) and autoclaved at $120^{\circ} \mathrm{C}$ for $15 \mathrm{~min}$. The resulting suspension was utilized as the fungal elicitor.

\subsection{Culture elicitation}

HP suspension cultures at the exponential phase were divided in groups. One group of flasks was kept as control. Two sets were treated on the 5th day of HP suspension culture with a final concentration of 100 and $25 \mu \mathrm{M}$ of MeJ and SA, respectively. The remaining groups were elicited on the 6th day with the fungal elicitor. Two of those sets were primed with $\mathrm{MeJ}(100 \mu \mathrm{M})$ or SA $(25 \mu \mathrm{M}), 24 \mathrm{~h}$ before fungal elicitor addition. The final concentration of the fungal biomass in the HP suspension cultures was $0.25 \mathrm{~g}$ dry $\mathrm{wt} / \mathrm{l}$. The priming and elicitation procedures were done in cells in the exponential phase, the growth period at which they were more responsive to treatments. Cells suspension culture samples were harvested by filtration on the 5th, 6th, 7th, 9th and 12th day of growth. The collected samples were lyophilized for $48 \mathrm{~h}$ and the biomass was stored in closed containers at $-20^{\circ} \mathrm{C}$ for further analyses. Each treatment contained three independent replicates and the experiments were repeated twice.

\subsection{Cell viability analysis}

Cell cultures were checked for their viability through out the experiment using the tripan blue (Sigma, Barcelona). Briefly, $0.1 \mathrm{ml}$ cells suspension samples were mixed with $0.1 \mathrm{ml}$ of $0.4 \%$ tripan blue (prepared in MS medium) and incubated for $10 \mathrm{~min}$. A part of the mixture after incubation was transferred onto a glass slide and covered with a cover slip. Cell viability was checked at light microscope. The percentage of cell viability for each sample was calculated by counting the number of non-stained cells in relation to the total cells at four different locations of the glass slide, in at least three independent replicates.

\subsection{HPLC samples preparation and analysis}

Dried HP biomass was extracted with an aqueous methanolic solution $(90 \%$ ) (at approximately $50 \mathrm{mg}$ dry wt $/ \mathrm{ml}$ ), with sonication for $20 \mathrm{~min}$, in the dark, at ambient temperature. An aqueous methanolic solution $(90 \%)$ was used to extract the dried HP biomass (at approximately $50 \mathrm{mg}$ dry wt $/ \mathrm{ml}$ ) with sonication for $20 \mathrm{~min}$ in the dark at ambient temperature. The liquid phase was filtered and submitted to HPLC-DAD analysis as described before (Dias et al., 1999). Quantification of the phenolic compounds was performed by the external standard method. Xanthones were quantified as mangiferin equivalents at $260 \mathrm{~nm}$. Flavonols and flavones were quantified at $350 \mathrm{~nm}$ as quercetin and luteolin-7-glucoside equivalents, respectively. Phenols analysis was also performed by HPLC-DAD-MS/MS as described elsewhere (Silva et al., 2005).

\subsection{Statistical analysis}

All the data were analysed by two-way analysis of variance test (ANOVA) with Bonferroni's post-hoc test. 
Statistical analysis and graphical representations were performed using Prism 4.0 software $\left(\mathrm{GraphPad}^{\circledR}\right.$, San Diego, USA).

\section{Acknowledgements}

This work was supported by a FCT grant (POCTI/ AGR/40283/2001). Conceição, L.F.R. was supported by a FCT grant (SFRH/BD/13318/2003).

\section{References}

Beerhues, L., Barillas, W., Peters, S., Schmidt, W., 2000. Biosynthesis of plant xanthones. In: Diederichsen, U., Lindhorst, T.K., Westermann, B., Wessjohann, L.A. (Eds.), Highlights in bioorganic chemistry. Wiley-VCH, Weinheim, pp. 322-328.

Beerhues, L., Berger, U., 1995. Differential accumulation of xanthones in methyl-jasmonate- and yeast-extract-treated cell cultures of Centaurium erythraea and Centaurium littorale. Planta 197, 608-612.

Braz-Filho, R., 1999. Brazilian phytochemical diversity: bioorganic compounds produced by secondary metabolism as a source of new scientific development, varied industrial applications and to enhance human health and the quality of life. Pure Appl. Chem. 71, 1663-1672.

Butterweck, V., 2003. Mechanism of action of St. John's wort in depression. What is known? CNS Drugs 17, 539-562.

Conrath, U., Pieterse, C.M.J., Mauch-Mani, B., 2002. Priming in plantpathogen interactions. Trends Plant Sci. 7, 210-216.

Cuyckens, F., Rozenberg, R., Hoffmann, E., Claeys, M., 2001. Structure characterization of flavonoid $O$-diglycosides by positive and negative nano-electrospray ionization ion trap mass spectrometry. J. Mass Spectrom. 36, 1203-1210.

Dempsey, A.D., Shah, J., Klessig, F., 1999. Salicylic acid and disease resistance in plants. Cr. R. Plant Sci. 18, 547-575.

Dias, A.C.P., Seabra, R.M., Andrade, P.B., Tomás-Barberán, F.A., Ferreira, M.F., Ferreres, F., 1998. Unusual flavonoids produced by Hypericum perforatum calli. Phytochemistry 48, 1165-1168.

Dias, A.C.P., Seabra, R.M., Andrade, P.B., Ferreira, M.F., 1999. The development and evaluation of a HPLC-DAD method for the analysis of the phenolic fractions from in vivo and in vitro biomass of Hypericum species. J. Liq. Chromatogr. 22, 215-227.

Dias, A.C.P., Seabra, R.M., Andrade, P.B., Ferreres, F., Ferreira, M., 2000. Xanthone biosynthesis and accumulation in calli and suspended cells of Hypericum androsaemum. Plant Sci. 150, 93-101.

Dias, A.C.P., Seabra, R.M., Andrade, P.B., Ferreres, F., Ferreira, M.F., 2001. Xanthone production in calli and suspended cells of Hypericum perforatum. J. Plant Physiol. 158, 821-827.

Dias, A.C.P., 2003. The potential of in vitro cultures of Hypericum perforatum and of Hypericum androsaemum to produce interesting pharmaceutical compounds. In: Ernest, E. (Ed.), Hypericum. Taylor \& Francis, London, New York, pp. 137-154.

Dixon, R.A., Paiva, N.L., 1995. Stress-induced phenylpropanoid metabolism. Plant Cell 7, 1085-1097.
Dixon, R.A., 2001. Natural products and plant disease resistance. Nature 411, 843-847.

Dmitriev, A.P., 2003. Signal molecules for plant defence responses to biotic stress. Russ. J. Plant Phys. 50, 417-425.

Erdelmeyer, C.A.J., Kock, E., Hoerr, R., 2000. Hypericum perforatum St. John's wort chemical, pharmacological and clinical aspects. Stud. Nat. Prod. Chem. 22, 643-716.

Felton, G.W., Korth, K.L., 2000. Trade-offs between pathogen and herbivore resistance. Curr. Opin. Plant Biol. 3, 309-314.

Feys, B.J., Parker, J.E., 2000. Interplay of signalling pathways in plant disease resistance. Trends Genet. 16, 449-455.

Freeman, S., Shabi, E., Katan, T., 2000. Characterization of Colletotrichum acutatum causing anthracnose of anemone (Anemone coronaria L.). Appl. Environ. Microbiol. 66, 5267-5272.

Gaudin, M., Simonnet, X., Debrunner, F., 2003. Colletotrichum gloeosporioides as the cause of St. John's wort (Hypericum perforatum) dieback in Switzerland and breeding for a tolerant variety. In: Ernest, E. (Ed.), Hypericum. Taylor \& Francis, London, New York, pp. 23-42.

Gibson, D., Sirvent, T., 2002. Induction of hypericins and hyperforin in Hypericum perforatum $\mathrm{L}$. in response to biotic and chemical elicitors. Physiol. Mol. Plant Pathol. 60, 311-320.

Hagemeier, J., Batz, O., Schmidt, J., Wray, V., Hahlbrock, K., Strack, D., 1999. Accumulation of pthalides in elicitor-treated cell suspension cultures of Petroselinum crispum. Phytochemistry 51, 629-635.

Hahlbrock, K., Bednarek, P., Ciolkowski, I., Hamberger, B., Heise, A., Liedgens, H., Logemann, E., Nürnberger, T., Somssich, I.E., Tan, J., 2003. Non-self recognition, transcriptional reprogramming, and secondary metabolite accumulation during plant/pathogen interactions. Proc. Natl. Acad. Sci. USA 25100 (Suppl. 2), 14569-14576.

Hostettmann, K., Hostettmann, M., 1989. Xanthones. In: Harborne, J.B. (Ed.), Methods in Plant Biochemistry, Plant Phenolics, vol.1. Academic Press, New York, pp. 493-508.

Izzo, A.A., Ernst, E., 2003. The clinical pharmachology of Hypericum perforatum. In: Ernest, E. (Ed.), Hypericum. Taylor \& Francis, London, New York, pp. 155-172.

Kitanov, G.M., Nedialkov, P.T., 1998. Mangiferin and isomangiferin in some Hypericum species. Biochem. Syst. Ecol. 26, 647-653.

Liu, B., Falkenstein-Paul, H., Schmidt, W., Beerhues, L., 2003. Benzophenone synthase and chalcone synthase from Hypericum androsaemum cell cultures: cDNA cloning, functional expression, and site-directed mutagenesis of two polyketide synthases. Plant J. 34, 847-855.

Schröder, J., 1997. A family of plant-specific polyketide synthase: facts and predictions. Trends Plant Sci. 2, 373-378.

Silva, B.A., Ferreres, F., Malva, J.O., Dias, A.C.P., 2005. Phytochemical and antioxidant characterization of Hypericum perforatum alcoholic extracts. Food Chem. 90, 157-167.

Tan, J., Schneider, B., Svatos, A., Bednarek, P., Liu, J., Hahlbrock, K., 2004. Universally occurring phenylpropanoid and species-specific indolic metabolites in infected and uninfected Arabidopsis thaliana roots and leaves. Phytochemistry 65, 691-699.

Thomma, B., Eggermont, K., Brockaert, W., Cammue, B., 2000. Disease development of several fungi on Arabidopsis can be reduced by treatment with methyl jasmonate. Plant Physiol. Biochem. 38, 421427.

Vivanco, J.M., Walker, T.S., Bais, H.P., 2002. Jasmonic acid-induced hypericin production in cell suspension cultures of Hypericum perforatum L. (St. John's wort). Phytochemistry 60, 289-293. 